\title{
RURAL EXTENSION IN LESS DEVELOPED COUNTRIES AND AREAS ${ }^{1}$ )
}

\author{
J. M. A. PENDERS \\ Inspector of the Agricultural Advisory Service, Netherlands Ministry \\ of Agriculture, Fisheries and Food
}

\begin{abstract}
SUMMARY
International co-operation in rural extension has been expanding in the post-war years on a scale which is promising for the future. In this connection attention may be drawn to the fact that, in 1949, the Food and Agriculture Organization of the United Nations held a conference on European agricultural advisory services in Belgium and the Netherlands. This marked the beginning of international co-operation in agricultural extension in this area, sponsored particularly by the Organization for European Economic Co-operation. Since 1953 the Netherlands Ministry of Agriculture, Fisheries and Food, together with the International Agricultural Study Centre and the Agricultural University, at Wageningen, have organized an annual international course of instruction in extension methods and programme planning. A new handbook on extension methods and extension programme planning is to be issued by the International Agricultural Study Centre (Secretary : Mr. A. H. HAak, Ritzema Bosweg 32, Wageningen).

This four-week summer school, born of the initiative of Prof. C. H. EDELMan and the author of the following article and supported by F.A.O., is attracting annually approximately 100 participants from about 20 countries throughout the world.

Lectures are given by experts from several lands, including members of the staff of the F.A.O. Ample provision is made for discussions, excursions and practical demonstrations with regard to the subjects dealt with, including a stay with Dutch agricultural advisory officers in their districts of operation.

The following article constitutes a lecture given by the programme co-ordinator of the summer school in July, 1955.
\end{abstract}

\section{INTRODUCTION}

Though the origin of rural extension dates back to the middle of the last century, most of the organized rural extension services were initiated in the present century, marking the transition to the scientific age in the fields of agriculture and rural welfare.

The organization, scope of activities, objectives and working methods of these extension services differ according to the influence exerted on them by the economic and social conditions of the peoples concerned. The historical background, e.g. the types of agencies responsible for foundation of the extension services (rural voluntary organizations, governments, institutions for resident teaching and research), also left its imprint on the services as we see them at present. The existing institutions for rural extension differ greatly in various countries, since they have developed out of the economic position and the intensity of agricultural production in the countries in question, and from the educational standard and social, traditional and cultural ideals of the respective peoples. Besides, changes to improve rural extension are bound to be gradual, like the changes in agriculture itself. Therefore no uniform pattern can or should be adopted. There is, however, a gradually growing unanimity of opinion amongst experts with regard to the basic principles on which effective rural extension should be based in both more and less developed

1) Received for publication July 27, 1955 . 
countries. This is revealed through reported studies, often carried out jointly as part of the expanding international co-operation in rural extension work during the post-war years.

The term "rural extension" has been purposely used instead of "agricultural advisory work", as the principles concerned are applicable to both agriculture and rural home economics, and even to advisory work among rural youth. Moreover, the term "extension" is more comprehensive and more widely known internationally, and has also been adopted with regard to technical assistance agencies.

\section{UNDERDEVELOPMENT, A VERY SIMILAR PROBLEM}

The problem of less developed countries has much in common with that of less developed areas in a more developed country, where the overall development did not, in general, proceed along harmonious lines. These very similar problems have attracted increasing attention in the years since the war, partly due to the enhanced social conscience of governments. In less developed countries and areas agriculture is often the main source of subsistence for a dense rural population with a more or less hidden surplus of labour on familyoperated farms which are generally small in size. Underdeveloped countries, and underdeveloped areas within countries, require assistance by joint international or national enterprise, respectively. Just as world peace can only be guaranteed if all countries are able to achieve a reasonable economic and social level, social peace in a country can only be ensured if all its socioeconomic groups are able to acquire reasonable social security.

The necessity for special assistance is obvious, because the gap between technically more or less developed - or, should we say, between "privileged" and "underprivileged" - countries seems to be widening rather than narrowing, whilst the same also seems to be true as regards more and less developed areas in a particular country, and even as regards more and less advanced farms in a certain area within a country.

I should like to quote here some sentences from the address on "The Prosperity of the World : a Common Responsibility", delivered by the Queen of the Netherlands in June 1955 to an assembly of Dutch youth and foreign students :

"The world population is steadily growing. But even now nnearly twothirds of the people in the world are inadequately nourished, and the difference between rich and poor areas is becoming more marked. Neither can allow the gulf between them to widen if their own interests are not to be harmed. If this development is not checked by wise planning we are all certain to be confronted with the consequences in the future. This danger overshadows the whole of human society and entails the danger that everyone of us may one day be its victim, no matter on what side of what curtain we are living......

The old saying : East is East and West is West and never the twain shall meet - may not and cannot be true any longer!"

Often, fundamental changes in conditions have to be effected, by improvement schemes which involve great financial expenditure. In rendering assistance the provision of adequate educational facilities, and consequently of 
rural extension, is of paramount importance, for the simple reason that it is ultimately the rural population itself which has to change its way of reacting to problems in the three spheres of knowledge, attitude and skills. It is, after all, human behaviour which has to be changed by education. This certainly involves more than increase of knowledge.

I may quote here a short paragraph from the address delivered by the President of the United States at the annual meeting of Land Grant Colleges Associations in November 1954.

"There is no aspiration, there is no dream on the horizon of man's hopes and beliefs and faith that is so strong, so vivid as the dream of peace, lasting peace. There are many things that must be understood, and many things that must be done, if we are to make progress towards the realization of that dream. But there is one thing, I think, that educators cannot afford to neglect, and that is the element of understanding as opposed to mere knowledge".

Whatever kind of rural development is planned and carried out - either in the sphere of land tenure reform, reclamation, consolidation of holdings and other land development works, or even industrialization and (e)migration - the people have to understand the necessity and meaning of such measures in order to become convinced of their value and induced to cooperate, whilst finally they have to become capable of adapting themselves efficiently to the rather rapid and great change in conditions, and of utilizing to the fullest extent the possibilities opened up to them.

Achievement of greater productivity in less developed countries and areas is often not primarily a matter of production techniques; the human factors related to social and cultural life, connected with manifold traditions, also have to be taken into account. Development may be defined as "a purposive adaptation to altered conditions in technical, economic, social and cultural fields or, vice versa, the purposive alteration of those conditions". One of the main criteria of development is defined as "the growth of man's control over the conditions of life, i.e., his natural environment, his society and himself".

There is still another aspect. Rural development schemes often involve great financial investments. If these are to yield a profit, the provision of adequate educational facilities, which require relatively little financial expenditure, are a necessary supplementary measure. Extension has to start in time, when the rural development scheme is still in the planning stage, and has to be provided also after the scheme has actually been carried out. Accordingly, education by rural extension based on teaching is an integral part of any rural development project. This may seem a slow, laborious way of doing things, but it is the only safe way to achieve real progress. Strengthening of rural extension facilities, and likewise of the tuition on which effective extension has to be based, will lead to greater productivity by shortening the time lag between the findings of research and their widespread application in practice.

Accordingly, available resources will be used more efficiently, which will result in greater output with decreased rather than increased production costs. This will not only provide a more stable foundation for the living standard of the rural population, but will, in the meantime, benefit the urban popula- 
tion. It is a means of expansion fundamentally different from, for instance, institution of trade barriers, which generally lead to higher production costs and less adjustment of the kind of production to market demands, thus hampering the final harmonization and selective expansion of production.

\section{ThE NEED FOR INTERNATIONAL CO-OPERATION}

It is in this field of rural extension activities that much could be gained by organized personal, direct contact between extension workers from more and less developed countries. The very fact that wide differences do exist between the extension services of the respective countries is surely the strongest argument for international co-operation. The more advanced countries are in a position to tell of the successes and... failures of their own development programmes, and to give information on situations in which one line of approach seems likely to be more effective than another.

By providing such help they too are likely to gain in experience, and may discover new techniques and methods more applicable to the less productive or backward areas and farms in their own countries.

By pooling experiences and views regarding rural, extension for less developed areas and backward farms, much could undoubtedly be gained by both more and less developed countries.

\section{The SMALL, FAMILY-SIZED FARM, THE MAIN ELEMENT}

As we know the small, family-operated farm is pre-dominent in less developed countries and areas. Extension activities therefore have to be focussed on the particular problems of this type of farm. Integration of these farms into the general plan for increased production and responsibility is a matter of considerable importance to agriculture in most countries. The small farmers tend to concentrate on the production of commodities with a high unit price, in particular on animal products and certain specialized crops such as fruit and vegetables, tobacco and vines.

Climatic conditions may have led to concentration on certain crops but, for many sound reasons, mixed farming is still the rule on the vast majority of small farms, where the degree of interdependence between crops is often very great, and which are dependent, to a varying degree, on feeding stuffs which the farmers have to buy.

\section{INTERDEPENDENCE OF TECHNICAL, ECONOMIC AND SOCIAL FACTORS IN EXTENSION}

Though the demographic and social aspects of these small farms, however important they are, cannot be discussed in detail here, there are two social aspects which need special attention in rural extension work: the more or less hidden surplus of labour normally existing on such farms, and the need for instruction in home economics. The surplus of labour, often the basic problem for these farms, can only be remedied to a limited extent by intensification of farming enterprise. This may even hamper final solution of the problem, if extension is restricted to the field of production techniques, as the temptation might grow to keep more family labour on the farm than would be desirable in the long run. As a consequence, this labour will often remain unskilled for other professions, either in the home country or abroad. Such surplus workers should be prepared and trained in good time - a point which 
raises questions as to the possibilities of industrialization and (e)migration. In more developed countries industry has to be spread, and also distributed to less developed areas within those countries. In less developed countries the establishment of rural industry has to be stimulated in the beginning.

In this connection there is still another aspect which should not be overlooked in rural extension work. The farmer's wife is often deeply involved in farming enterprise. The immediate effect of home economics extension should be an improvement in "home-making" technique; but both home economics extension, and extension work among rural youth, may perform yet another useful function by influencing the farmer, via the other members of his family, into becoming more willing to depart from his traditional way of thinking, which is often the main obstacle to improvement of the farm. He may therefore be induced to co-operate more wholeheartedly with the agricultural extension service in order to increase his earning power, on which other worthy aims are ultimately contingent.

\section{THE NEED FOR ADEQUATE EDUCATIONAL FACILITIES AND APPLIED RESEARCH}

It may be noted that, in dealing here with rural extension for less developed countries and regions, it is presupposed that adequate facilities for general education and vocational training are provided, as these will always be the basis on which the superstructure of rural extension as an out-of-school "roadside" education system can act efficiently. Elementary general education and institutes for primary vocational education, in both agriculture and rural home economics, are of primary importance in this respect. Means of knowing "why" have to precede means of knowing "how". Extension personnel may be engaged actively in providing vocational courses for the older youth and for adults. which courses will form a link between more theoretical teaching and practical extension work, respectively.

Exchange of farmers' sons in temporary employment within national boundaries is an important way of stimulating mental mobility. An exchange of advisers on an international scale, preferably between countries under approximately similar conditions, is also to be recommended.

In addition, research has to be directed to solving the most urgent and most real problems prevailing in the less developed countries and areas; this presupposes a thorough survey of the regions concerned in the technical, economic and social fields, and intimate contact with the rural population. Extension personnel may be of substantial help in this respect. They may carry out a great deal of regional experimental work adapted to regional and local differences in soil, climate and ways of farming. They may even be engaged in managing regional sub-stations for research in a certain branch of agriculture. Extension specialists may act as a link between the extension officers in the field and the institutes for applied research in a certain branch of agricultural science. Close co-operation between extension, education and research must receive particular emphasis in less developed countries and less developed areas within countries.

\section{Conditions to BE FULFILlED}

Other necessary prerequisites in both the technical and social and economic fields have to receive full attention, if rural extension is to function effect- 
ively. As regards the former field of activity, adequate facilities for analysis of farm requisites, preferably at moderate cost, may be mentioned, in order to ensure that the farmer can obtain a guarantee as to the quality of important instruments of production. Laboratories for testing soils, fertilizers, feeding, stuffs, seeds, insecticides, agricultural machinery and implements, household equipment, etc., are important in this respect, as they provide the necessary factual data on which efficient farm and home management has to be based. Extension personnel may stimulate the demand for such services, and even, in the beginning, be actively engaged in carrying out this routine work. Such people may, furthermore, stimulate the establishment of societies on a co-operative basis among the farming population, so that the farmers themselves may exert some influence on buying and selling, and on the credit market, which is particularly valuable to small farmers. Farmers' co-operatives have, in fact, exerted a beneficial influence on the quality of agricultural products.

Finally, it is up to governments to establish sound agricultural policies aiming at improving overall agricultural productivity; at raising the living standards of the entire rural population; and at avoiding the very real danger of creating backward agricultural areas and forgotten rural groups. Such policies benefit incidentally both the urban and rural populations by strengthening the national economy and increasing welfare, due attention also being paid to world-wide developments, in order to avoid less desirable and less efficient production trends and techniques.

As some vital conditions for greater productivity are beyond the power of the rural population itself to establish adequately, government policy may include regulations regarding the land tenure system and the quality of agricultural requisites and products, and also provisions for reallocation of land, land development works, industrialization and emigration.

In development activities it is necessary to make a clear distinction between : improvements in farm and home management as such, which the farming population can influence, and improvements in production conditions as a basis for improvement in management, which exceed the capacities of the individual farmers and therefore require special assistance. The first category of improvements may be influenced by the individual farmer and his wife, and can perhaps in co-operation with other members of the farming population, be substantially promoted by adequate research, teaching and extension facilities. The second category of improvements frequently require special measures to be taken by the government and public bodies, often on a wider scale, before the individual farmer and the farming population can improve efficiency in farm and home management.

A factor which is certainly important in this respect is land tenure policy, which can be influenced by the government so as to ensure that both owners and occupiers get their reasonable share of profit from the land. Such government action should also aim at preventing, as far as is possible, less efficient utilization of the land.

\section{Possible ways of INCReasing productivity by EXTENSION aCTIVITIES}

The possibilities of expanding a cultivated area to any considerable extent may be rather limited, but production can nevertheless be greatly increased 
in an efficient way by land improvement and more intensive cultivation of the land in actual use, taking into account the surplus of labour existing on many small farms. This possibility is confirmed by the great differences in average yield of main crops and livestock, both within a country and between countries, which differences are greater than those normally to be expected as a result of variations in natural conditions. It is interesting to remember in this connection that differences in productivity within a country are sometimes as great as those between countries.

To illustrate this by an example from Europe, we may quote that, in the various countries, the average production of wheat per hectare varies from 6.5 to 30 quintals, and of potatoes from 70 to 265 quintals, respectively, whereas the average annual milk production from dairy cattle ranges between 550 and $3,950 \mathrm{~kg}$. In many less developed countries and areas farming methods and equipment could undoubtedly be better adapted to natural conditions by efficient utilization of the available resources, without excessive financial investments being involved. There is ample room for improvement in the use of fertilizers, improved seed and animal strains, insecticides, etc., the costs of which will be relatively small. The well-known relatively high consumption of fertilizers in the Netherlands, amounting on the average to $200 \mathrm{~kg}$ of $\mathrm{N}_{2} \mathrm{O}_{5}$ and $\mathrm{K}_{2} \mathrm{O}$ per hectare, is only to some extent due to natural conditions of soil and climate. Nor do economic factors play the most important role in this respect, as the ratio of prices of agricultural products to those of fertilizers in this country lies between the extremes of the other European countries. It is ondoubtedly owing to an intensive agricultural extension campaign that, for instance, the average application of nitrogenous fertilizers on grassland in the Netherlands has surpassed the pre-war level by more than $100 \%$.

Though, in quoting these statistics, we have restricted ourselves to a small part of the world, it should be borne in mind that Europe provides an excellent example of both national and local contrasts in the social and educational status of farmers. There are also sharp differences in efficiency of production and marketing, in the quality and utilization of land resources, and in climate and soils. There are perhaps more language barriers and political difficulties, and more different currencies and frontier contracts than are to be found in any other continent. Nevertheless, the results achieved already, in spite of these conditions, in the field of inter-European co-operation, particularly with regard to rural extension, are promising for future work all over the world.

We should not exaggerate the possibilities of mechanization, and particularly motorization, on the small farms, which in many cases already suffer from a surplus of human labour. As the use of animal draught power will continue to play an important role, the adoption and technical development of animal-drawn equipment for use on small farms should be carefully examined. In order to alleviate the peak loads in the matter of labour, more expensive and heavy machinery could advantageously be used, on a collective basis or via contract services. More attention should be paid to the utilization of efficient implements and simplification of work, in order to increase labour productivity, thus raising not only output per acre but also per man. In extension work, this aspect of the problem is often neglected, particularly as regards

2) One quintal $=100 \mathrm{~kg}=220.46 \mathrm{lb}$. 
the small, family-sized farms, in the case of which insufficient attention is paid to the factor of family labour.

A feature which often hampers the productivity of small farms is their excessive subdivision into plots, which are inefficient in size and shape and widely scattered. The extension servuce has an important role to play in stimulating the demand for consolidation among the farming population, and in adapting that population to the rather rapid and great change taking place in conditions when the consolidation scheme is put into effect. The government should, via the appropriate agencies, provide facilities for carrying out an efficient consolidation scheme - which may, incidentally, include water control, the opening-up of the areas concerned by means of roads, electrification and provision of telephone communications - and thus bring about a total reconstruction of the areas if necessary.

The availability of adequate credit facilities for the small farms, and especially for those of the peasant type, is one of the most important prerequisites for their improvement. Alterations in the system of management of a farm will bring with it great financial problems for many small farms, even when decisions are taken primarily to pay attention to those measures which will yield immediate profit with relatively light financial expenditure and therefore will only need short-term credit. As regards the latter, the extension service can exert a great influence. It may furthermore be desirable for the government to establish a guarantee fund to meet the difficulty as to security for long-term credit demands, which security could then be granted to farmers carrying out well-defined projects for efficient intensification of the productivity of their holdings.

Though the nature of the extension service is primarily educational, it might be given the assignment of judging the application of such credits, as this administrative task is not reminiscent of government inspection, suspencion of which might destroy the confidence of the farmers, on which effective extension will always be dependent. It is not necessary to enlarge on the fact that land tenure policy will have a great effect on longrange capital investments on the farm.

\section{EXTENSION METHODS TO BE USED}

Extension methods have to adapt themselves to conditions on the small farms and among their population. Under circumstances of ever-increasing intensive production, concentrating on commodities with a high unit price (e.g. animal products and specialized crops), which is the logical trend for small farms out to gain a sufficient family income, the managerial capability of the farmer is really put to the test. This is particularly true as regards mixed livestock farms, where the fodder produced does not constitute end products. Extension and tuition in farm economics therefore has an increasingly important role to play with the rise of the technical production level. The input-output relations which are rather easy to grasp at the extensive production level, become more complicated at the intensive level. Ultimately, the increase in total output inevitably results in a higher income for the farm as whole; the farm should be viewed as a business unit rather than as a combination of unco-ordinated sectors. A systematic plan for expanded farm economics extension (if need be on a less elaborate scale), including marketing, 
is therefore of great importance for small farmers who are intensifying production.

As has already been said, in view of the fact that the farm family, particularly on a small farm, is an intimate living and working unit, much is to be said for close co-operation between general agricultural extension, rural home economics and rural youth extension work, in regard to small farms.

Balanced farming as an extension goal, and the farm-family approach in extension work, are of particular value in connection with small farms. It should be remembered that technical, economic and social factors are closely interrelated on such farms, and extension agencies should therefore deal with the problems in all these fields.

It is with regard to the small farms, in particular, that the extension service has to use individual extension methods in order to induce the farmer to change his traditional way of farming. Visits to farms, though expensive from the point of view of the time involved, therefore have an important role to play. In this respect more use could be made of carefully selected, nonuniversity-trained, farm-raised experts acting as local assistant extension officers, guided and directed by university-trained regional extension officers and backed by extension specialists at the appropriate levels. The establishment of extension associations, and the building-up of local leadership in extension among the rural population, will also be worth-while means of expanding the individual approach. Formation and use of local leaders is an aspect which deserves particular attention and.... critical judgement, in so far as care must be taken to avoid partiality to any especial group, since extension should be made an instrument of social progress in the interest of all.

As regards group methods in extension, demonstrations on the farm will be of outstanding value in persuading the farming population to improve management of their farms and homes.

As to the managerial side, pilot farms and test farms - on which the ultimate result of a basic farm enterprise is tested both technically and financially for several years - are of great importance. Pilot villages and pilot regions are also of great value in showing what can be gained by efficient co-operation on the part of the rural population. They are also valuable in attracting public attention, and help to raise the standard of rural welfare in the community.

The group approach to several farms is an effective working method, as it has special psychological merits. It has the advantage that members of the farming population may draw upon each other's knowledge, thus avoiding to a great extent the risk that some will remain backward, which may otherwise easily be overlooked. The competition system between various farms is an excellent way of attracting attention, and of inducing individuals to pass beyond traditional bounds.

Mass methods in support of the other two extension methods have to be selected carefully and adapted to the educational level of the populations concerned.

It should always be borne in mind that extension methods, to be effective, should be adapted to the conditions prevailing, which conditions may differ even within one village. Therefore, no uniform system can or should be adopted. The very fact that less developed areas, backward farms and forgotten rural 
groups exist in more developed countries which have carried out rather intensive extension work, is certainly a proof that extension overlooked these problems, which are at present coming to the fore.

It is found that "tradition" plays a dominant role in less advanced countries and areas. In this connection it is the style or the way of farming that matters. This style is rather uniform, irrespective of differences in the resources and sizes of the farms in a certain area.

The system of extension generally applied in the. past may be referred to as the "draw system". By means of samples the attention of the farming population was "drawn", as it were; and it was supposed that they would then automatically turn to the extension service for assistance. Hence the farming population was not advised until it actually asked for advice. The extension services were somewhat inclined to carry on a kind of passive activity, waiting for the people to request advice rather than stimulating a demand for help. This system is a safe one and has given valuable results in practice. It avoids the risk of appearing importunate, which may exert a detrimental effect on the necessary goodwill of the farming population with regard to the extension service.

But it should be borne in mind that extension services based only on supplying advice on request never accomplish much towards increasing overall agricultural productivity and improving the general living standard of the rural population as a whole. The very existence of less advanced farms and, moreover, less developed agricultural areas and forgotten rural groups, in more developed countries where extension services have long been on a rather intensive scale, is a sign that something more is required. There is certainly a need for extension workers, particularly in less developed countries and districts, to act as development officers, in performing which function they could survey from time to time the overall needs of their areas and devise means of stimulating action among the farming public for solving the problems of the area. This may be called the "push system". To be effective, extension work as a whole has to use both systems simultaneously. Finally, there is much to commend the planning of overall development schemes, of which co-ordinated comprehensive extension programmes form an integral part, and on which development schemes such programmes therefore have to be based.

\section{The NEED FOR PROGRAMME PLANNING AS A COMPREHENSIVE EXTENSION APPROACH}

Just as a school must have its curriculum, through which it attains certain specific educational objectives, so must an extension service have a definite and constructive extension programme, if it is to make its maximum possible contribution to rural progress.

This will avoid haphazard extension enterprises and ensure a more systematic working procedure along thoroughly planned lines, thus constituting a more rational approach to extension work.

Extension programme planning is a comprehensive and most efficient working method, particularly when applied to less developed countries and areas. It will almost automatically ensure an integrated extension approach, so essential in this respect. Special emphasis may be placed on the importance of a many-sided and integrated approach, and on the importance of closely asso- 
ciating agricultural improvement with the general progress of the rural community as a whole.

Recognition of both these principles is implicit in the plans for community development in India, under which multi-purpose extension workers are stationed in the villages as part of an overall programme of community development. Similarly, pilot regions in France, thoroughly planned in less advanced areas, have shown a remarkable development of late years. Based on the same principle, the pilot villages recently established in the Netherlands in areas where small mixed holdings predominate have already achieved valuable results in raising the general level of farm and home management, and the living standards of the entire community. Balanced farming associations, as started in Missouri (U.S.A.), may also be mentioned in this connection.

It is worth while listing some basic principles of extension programme planning, as established in the United States, which might profitably be adopted by other countries as well.

Extension programmes should be based on careful analysis of factual situations and keyed to the existing technical, economic and social level of the rural people of the area. They should be comprehensive and include problems of interest to all members of the rural family and to all social and economic groups. They should be flexible, in order to cope with long-term situations, abrupt changes, and special emergencies, and should select for immediate action those problems which relate to recognized needs, thus dealing with known, concrete conditions. As extension is, in essence, primarily educational, the programme should be directed towards bringing about an improvement in the ability of people to solve their own problems, individually and collectively. Maximum use should be made of voluntary leadership in the planning as well as in the execution of extension programmes. Clear definition of objectives in terms that people can understand will, in the meantime, ensure evaluation of results achieved. To remain realistic the programme should be practicable from the point of view of personnel available, finance, time, and other factors. Furthermore, a distinction has to be made between the permanent or constant part of the programme; the longterm part; and the annual plan of operations, which contains a specific list of a limited number of problems to be tackled in the current year. Finally, much is to be gained through coordination of local extension programmes at regional and national levels, and through the joint participation of the representatives of the rural population and the entire extension staff in endeavouring to accomplish the basic task of "helping the farming populations to help themselves". Although co-ordination in the planning of rural extension work is most important, also decentralisation in the execution of the work is necessary in order to cover the regional problems adequately and to avoid burocracy in extension.

It is a very real challenge which confronts the rural extension services in both more and less developed countries - to face and attack, through joint enterprise, the very real problem of less developed countries and less advanced areas, backward farms and forgotten rural groups in more developed countries. 


\section{BibLIOGRAPHY}

Farmers of the World. Columbia University Press, New York, 1945.

Diagnosis and Pathology of Peasant Farming. Proceedings of the Seventh International Conference on Agricultural Economics, Oxford University Press, 1950.

Conference Report on Extension Experiences around the World, U.S.D.A., Washington, 1951.

Methods of Agricultural Extension. International Agricultural Study Centre, Wageningen (the Netherlands), 1953.

The Farm and the City - F.A.O., Rome, 1953.

Maunder, A. H. : Improvement of Agricultural Extension Services in European Countries. F.A.O., Rome, 1954.

Development of the Agricultural Advisory Services in Europe since 1950. O.E.E.C., Paris, 1954.

Problems of Food and Agricultural Expansion in the Far East - Working Paper for the F.A.O. Regional Consultation on the Selective Expansion of Agricultural Production and Consumption in Ceylon, F.A.O., Rome, 1955.

Beukering, J. A. van: Regional Development and Agricultural Extension. Netherlands Journal of Agricultural Science, 3 (1955) 93-99.

Kersey, L. D. \& C. Ch. Hearne : Cooperative Extension Work. Cornell University Press, Ithaca, 1955. 